\title{
Mitigating the Bridge End Bump Problem: A Case Study of a New Slab System with a Lower Partition Slab-Pile Foundation
}

\author{
Yu Yang, Chuang Yu, Ze-xiang Wu (D, and Dong-mei Tu \\ Collage of Civil Engineering and Architecture, Wenzhou University, Wenzhou 325035, China \\ Correspondence should be addressed to Ze-xiang Wu; zexiang.wu@wzu.edu.cn
}

Received 28 January 2020; Accepted 20 April 2020; Published 31 May 2020

Academic Editor: Xue Zhang

Copyright $\odot 2020$ Yu Yang et al. This is an open access article distributed under the Creative Commons Attribution License, which permits unrestricted use, distribution, and reproduction in any medium, provided the original work is properly cited.

\begin{abstract}
This paper describes a case of using a pile-slab composite foundation to handle a bridge-end bump problem. Conventionally, a deep-seated concrete slab method is employed to tackle this problem; however, this method generates a large stress concentration within $1 \mathrm{~m}$ from the bridge end. The mechanical bearing capacity of the deep-seated concrete slab is insufficient and prone to structural damage. Further, the longitudinal slope change rate is also very high. To overcome these limitations and solve the problem, a lower partition slab-pile foundation treatment method is proposed. The construction of the proposed method is provided, and the results of a case study analyzed by field monitoring and a simulation executed using ABAQUS finite element simulation show good agreement. The results indicate that the mechanical bearing characteristics for the proposed lower partition slab-pile foundation treatment method are better than the conventional deep-seated concrete slab method, and therefore, the structure is more resistant to damage. In addition, because the pile foundation enhances the foundation bearing capacity, the longitudinal slope change rate of the new pile-slab composite foundation is 2.5 times that for the deep-seated concrete slab technology. Thus, the lower partition slab-pile foundation treatment method can better deal with the bridge end bump problem.
\end{abstract}

\section{Introduction}

Rock and soil scholars have attached considerable importance to the research on the stability and settlement of soft soil foundations on highways. In actual engineering, the problem of bridge end bump caused by a soft foundation settlement has been difficult to control and solve, and several researchers have attempted to resolve this problem.

Wong and Small [1] constructed slabs at an angle to reduce the problem of a bump forming at the end of the slab. Shi et al. $[2,3]$ performed a 3-D finite element analysis considering the interaction between the approach slab and the embankment soil, and they found that, when the slab is separated from the soil, the approach slab is under a state of destruction. Robison and Luna [4] used finite element analysis to explore soil embankment-bridge structure differential settlement in two Missouri bridges and provided recommendations for the construction sequence. Chen et al. [5] specifically studied the cracking of the approach slab under the load of a vehicle. Roy and Thiagarajan [6] conducted a numerical analysis to study the extent and location of cracks by performing a nonlinear finite-element analysis of the slab.

Based on the current application status of the treatment method, the bridge end bump problem still occurs and affects normal use and the durability of the road bridge. An effective method to determine and treat the bridge end bump problem is still required. The traditional bridge approach slab technology has several limitations, such as it is very easy for the bottom of the slab to separate from the soil, which is not conducive to slab deformation and bearing. Therefore, it is necessary to improve the traditional bridge approach slab and optimize the slab layout and structural design.

Nassif et al. [7] proposed a new design scheme, and the testing, long-term monitoring, and finite element analysis were carried out to prove that the new design has better bearing performance than the existing slab design. Yi-qiang et al. [8] proposed a deep concrete slab treatment method; the concrete slab was placed at a certain depth to improve the stress distribution and deformation of the bridge end 
subgrade. Chen and Abu-Farsakh [9] proposed a new design for the approach slab: improve the bending rigidity of the slab using reinforced soil foundation (RSF) to support the slab and traffic loads at the roadway pavement/approach slab joint (R/S joint). Puppala et al. [10] recommended using expanded polystyrene (EPS) geofoam as an embankment fill material, based on monitoring and modeling studies, as an effective measure to mitigate the differential settlements under a bridge approach slab.

Simultaneously, many scholars proposed using the pile foundation to improve the foundation bearing capacity to reinforce the bridge foundation. Lin and Wong [11] studied the composite foundation of variable length cement mixing pile to deal with the problem of bridge end bumping on the expressway. Through field and laboratory tests, it was found that a variable length cement mixing pile was simple and effective in treating the difference of the settlement of the bridge end embankment. For old road renovation and maintenance projects on a soft soil foundation, the corresponding embankment piles were treated by Gunalan et al. [12]. According to the field test and monitoring data, the interaction between the bridge foundation and the foundation is analyzed in detail. Bakeer et al. [13] adopted a treatment method combining the pile foundation and approach concrete slab, which improves the integrity of the treated foundation and has an obvious effect on preventing the bridge end bump caused by poor settlement. Zhang et al. [14] developed a fixed-geosynthetic-reinforced and pilesupported embankment (FGT embankment) to eliminate the differential settlement between a bridge and an adjacent backfill embankment. The comparison of the results of the field measurement studies and traditional (CT embankment) and (GR embankment) methods shows that the FGT embankment was more effective at ground improvement. Xiao et al. [15] performed a series of three-dimensional (3D) centrifuge model tests on an approach embankment over a silty clay deposit improved by cement-fly ash-gravel (CFG) piles combined with geogrid. Further, numerical studies were conducted $[16,17]$, which indicate that the performance of the abutment piles is significantly improved when reinforcing the ground with CFG piles beneath the approach embankment as it helps minimize the risk of the bump at the end of bridge.

The study found that, because the settlement of soft soil foundation cannot be avoided, the key to the problem lies in how to develop a good settlement coordination deformation treatment technology. Based on the research on the bridge end jumping problem, this paper proposes a new type of soft ground-based highway bridge end jumping treatment technology-lower partition slab-pile foundation-and the reliability of the technology was verified for practical applications. Through field engineering monitoring and numerical simulation prediction, the actual and theoretical predictions are, respectively, verified. The working characteristics of the lower partition slab-pile foundation were analyzed and compared with the previous different treatment technologies, which verified the effectiveness of the technology. It provides a reference for the handling of the bridge end bump problem in the future.

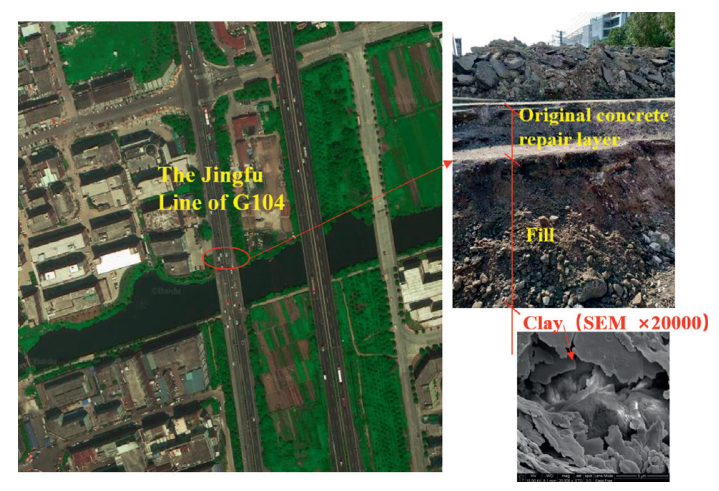

FIgURE 1: Original foundation excavation diagram of the bridge end section.

\section{Lower Partition Slab-Pile Foundation}

2.1. Field Case of National Highway 104, Wenzhou. A typical soft foundation bridge built on the Jingfu Line of the G104 National Highway in Ouhai District, Wenzhou City, Zhejiang Province, China, was selected for the case study (Figure 1). The bridge is located at K1934 + 813 on the G104 National Highway and is an important traffic node. Since the bridge end subgrade were not treated before, onsite investigations revealed problems such as bones and potholes on the bridge deck, deterioration of the bridge deck, and extremely large abutment due to settlement and large gap seepage was identified. Further, there are also several obvious cracks. In the bridge section, there are problems such as subgrade expansion joints and upper slabs and geological problems that lead to the bridge end bump problem.

The project site is located in Wenzhou City, which is located in the southeast coast of the Zhejiang Province. The Wenzhou plain is surrounded by mountains and seas and has a flat topography. Its shallow strata are quaternary marine sediments, lake sediments, and their transitional alluvial sea sediments, lake sediments, and weak strata, which are relatively thick, generally about $30 \sim 65 \mathrm{~m}$. The lithology of the stratum includes soft soil, clay soil, silt soil, and fine sand. Among them, the soft soil layer has the greatest impact on the construction of the project, and it includes silt and silty clay soil, which is widely distributed in the plain area, has a large thickness, and has extremely poor engineering geological properties.

2.2. Details of Slab-Pile Composite Foundation. No treatment method was employed on the original bridge end subgrade. During maintenance and repair, the asphalt was flattened to eliminate the settlement. However, this treatment does not solve the problem of bridge end jumping. Further, this leads to problems for driving/travel comfort and continuous rework and maintenance. There is a constant increase in repair cost and inconvenience to everyday travelers, which causes a poor social impact, increased labor, and added expenditure. Thus, to overcome these problems, the original surface asphalt layer has now been removed, and a new bridge end subgrade treatment plan is designed. 
Owing to the soft soil quality of the foundation at the project site, a large settlement will occur under the action of the upper load. Thus, excessive bridge settlement can easily occur between the rigid foundation bridge and the flexible foundation road, causing the bridge end to bump. Different designs are recommended to improve the control of the settlement curve of the bridge end subgrade and to alleviate the bridge end bumping effect. To this end, it was decided to use the lower partition slab-pile foundation scheme to control the soft foundation of the bridge end to alleviate the phenomenon of the bridge end bump problem.

(a) Step 1. The construction scope of the road and bridge junction section is combined with the length of the lower partition design section of $10 \mathrm{~m}$ and the excavation step treatment. The length of the excavation of the bridge end subgrade is $11 \mathrm{~m}$, and the sides are excavated to the curb or soil shoulder. The width of the lower partition is smaller than the width of the road.

(b) Step 2. The minimum excavation depth of the roadbed is $2 \mathrm{~m}$. After aexcavating to the design elevation, a flattening treatment is performed. A $10 \mathrm{~cm}$ gravel and other water-permeable materials are laid on the bottom of the foundation pit as the working construction surface. After completion, the bored pile is set.

(c) Step 3. The bored pile is $50 \mathrm{~cm}$ in diameter and is arranged in two rows of six. The concrete strength grade of the pile body is $\mathrm{C} 30$, and the maximum length of the single root is $32 \mathrm{~m}$. The top of the pile is reserved for the connection with the bolster. After the construction is completed, the top of the pile is leveled and a gravel cushion with a thickness of $20 \mathrm{~cm}$ is laid.

(d) Step 4. The reinforced concrete bolster is casted according to the reserved steel bars at the top of the pile. The bolster beam is made of C30 concrete. A total of three bolsters are installed. After the bottom of the third bolster is compacted, the pile foundation is not provided. The first bolster is reserved for connecting the steel bar with the lower partition slab, and the outer part is sheathed with a PVC pipe to ensure that the lower partition can rotate at a certain angle around the lap joint, and the latter two bolster beams are not reserved for connection with the lower partition slab. The rebar is in free-standing ends. After the bolster beam maintenance strength meets the specification requirements, the slag is properly backfilled and compacted to the bottom of the lower partition slab.

(e) Step 5 (Figure 2). The lower partition slab is completed using a C30 reinforced concrete cast-in-place. The steel grade is HRB400 steel. The lower partition slab is $10 \mathrm{~m}$ long, $5 \mathrm{~m}$ wide, and $30 \mathrm{~cm}$ thick. After the lower partition slab is cured to meet certain strength requirements, the upper embankment is filled. A $2 \mathrm{~cm}$ construction joint is reserved between the lower partition slabs, which is filled with an asphalt batt and a double-layer steel-plastic grid placed at the joint seam to prevent crack reflection.

(f) Step 6. After the maintenance strength of the lower partition slab meets the specification requirements, the slag filler with good water permeability is backfilled and compacted to the bottom surface of the pavement layer.

To verify the design assumptions and monitor the performance of the lower partition slab-pile foundation, various instruments were installed on-site. The field monitoring plan was continuously monitored from the completion of the construction of the slab to the opening of the vehicle. The installed instruments include the following:

(a) Settlement: as shown in Figure 3, settlement monitoring is performed on the corresponding important node of the pile-slab structure, that is, where the pillow beam is located, three settlement observation points are set on the bridge end road surface $(\mathrm{C} 1, \mathrm{C} 2$, and C3). The settlement of different positions of the bridge end is monitored; the observation points are located at 5,10 , and 15 , respectively, from the bridge.

(b) Soil pressure: a soil pressure box is used to measure the vertical load shared by the lower partition slab and the surrounding soil. Under the two lower partition slabs, two soil pressure boxes are buried under the two lower partition slabs to determine the stress of the board and whether the soil under the slab will be emptied. Soil pressure box measurement range: $0.1-1.0 \mathrm{MPa}$. The calculation formula is $P=K\left(f_{i}^{2}-f_{0}^{2}\right)$, where $P$ is the measured soil pressure value $(\mathrm{kPa}), f_{i}$ is the current reading of the pressure sensor $(\mathrm{Hz}), f_{0}$ is the initial reading of the pressure sensor $(\mathrm{Hz})$, and $K$ is the calibration coefficient of the pressure sensor $\left(\mathrm{kPa} / \mathrm{Hz}^{2}\right)$. All instruments are installed after the pile is constructed and before the slab is constructed. The soil pressure sensor is monitored by a portable tester.

\section{Finite Element Analysis}

3.1. Finite Element Model. In this paper, ABAQUS is used to simulate the numerical simulation of the project at the junction of road and bridge using the lower partition slabpile foundation method and the deep-seated concrete slab method to establish a two-dimensional (2D) analysis model (Figure 4).

Select a typical section for simulation analysis. The length of the pavement is $20 \mathrm{~m}$ and the depth is $46 \mathrm{~m}$, which can eliminate the influence of boundary effects on the simulation results. The total number of grids is 41,490 , of which the number of soil elements is 38,827 , the number of pile-slab composite foundation elements is 1,200 , the number of elements in the slag layer is 1,197 , and the number of elements in the pavement layer grids is 266 . The indexes of the soil layer required for the modeling are obtained according to the engineering survey report and 
TABLE 1: ABAQUS finite element simulation material parameters.

\begin{tabular}{lcccccccc}
\hline Material & Model & $E(\mathrm{MPa})$ & $\nu$ & $\lambda$ & $\kappa$ & $M$ & $e$ & $K_{w} \times 10^{-4}(\mathrm{~m} / \mathrm{day})$ \\
\hline Silty clay & MCC & 3 & 0.35 & 0.42 & 0.03 & 0.498 & 1.618 & 24.3 \\
Muck & MCC & 0.8 & 0.33 & 0.42 & 0.01 & 0.45 & 1.03 & 8.64 \\
Clay & MCC & 4 & 0.35 & 0.22 & 0.02 & 0.406 & 1.27 & 8.14 \\
\hline
\end{tabular}

laboratory tests. The soil layer parameters are shown in Table 1. Among them, the soil adopts the modified cam-clay model. The modulus is $30 \mathrm{GPa}$, Poisson's ratio is 0.2 , the pavement elastic modulus is $1.4 \mathrm{GPa}$, Poisson's ratio is 0.2 , the backfill soil layer's elastic modulus is $14 \mathrm{MPa}$, and Poisson's ratio is 0.35 . The pile-soil contact uses surface-tosurface contact, the normal contact is hard contact, the tangential contact is penalty contact, and the friction coefficient is 0.35 . The other contacts are all hard contacts. First, the geostatic analysis step on the overall model to get the correct initial stress field is used, and then the soil analysis step to consider the pore pressure dissipation is used, and the settlement treatment effect at different times is simulated and then analyzed. After the bridge was opened to traffic, the load is equivalent to $10.5 \mathrm{kPa}$ and the total analysis time is 730 days.

3.2. Simulation Results. Figure 5 shows the vertical stress, vertical displacement, pore pressure, and displacement vector results of the first day and the 730 days of the ABAQUS simulation. It can be concluded from Figure 5 that the vertical stress does not change considerably and concentrated stress is generated at the joint of the pile slab. The vertical displacement gradually increases with time, and as the distance from the bridge end increases, the displacement also increases. When it is just open to traffic, the excess pore water pressure is generated and the maximum value is $10.46 \mathrm{kPa}$. With the development of consolidation, the pore pressure has basically dissipated at 60 days. The deformation vector gradually increases with time, the maximum is $19.45 \mathrm{~cm}$, gradually decreases with depth, and increases with distance from the bridge end, and reaches the maximum at the end of the treatment section, indicating that the pile-slab composite foundation can completely handle the settlement.

3.3. Monitoring Results and Predictive Analysis. The settlement and soil pressure monitoring data are consistent with the simulation results, and all values tend to be stable after two months. Figure 6 shows the settlement simulation results and the monitoring data. The results are basically the same. The settlement of the top surface of the embankment becomes larger with an increase in the foundation settlement. Simultaneously, the settlement curve of the top surface of the subgrade after the treatment of the pile-slab composite foundation is parabolic in the treatment area of the bridge end. The slope and range of the curve are related to the settlement value of the foundation. First, the load on the bridge end was found to be repetitive, and therefore, the settlement was more obvious. However, over time, the overall stiffness of the bridge section increased further; the untreated zone had smaller stiffness and the settlement was obvious. The tail of the slab was the free end.

Figure 7 shows that the soil pressure simulation results and monitoring data, and the rules are relatively consistent. When the construction is completed and the vehicle passes, the entire pile-slab composite foundation is gradually stressed and begins to work. The soil pressure box is compressed by the lower partition slab and begins to be stressed. The value gradually increases and finally reaches stability. The mesh of the soil and pile-slab composite foundation is always in contact, so there is no gradual force process, but the final results on both sides are not much different. Under the upper load, the two piles at T1 bear most of the upper load, and the soil pressure at $\mathrm{T} 1$ is relatively stable, which gradually increases from $20 \mathrm{kPa}$ to $33 \mathrm{kPa}$. The right side of T2 is the free end, the settlement is large, the soil pressure at T2 gradually increases with time, and the soil pressure is greater than T1, and it gradually develops from $27 \mathrm{kPa}$ to $48 \mathrm{kPa}$ and tends to be stable after 60 days.

It can be seen from the data of the settlement and soil pressure that, under the upper load, the soil is consolidated in two months and the overall structure is relatively stable. In addition, the pressure and settlement of slab 2 are greater than those of slab 1, and the effect of the treatment is in accordance with the expected assumption, which helps the settlement achieve a smooth curve transition.

\section{Mechanical Behavior of Lower Partition Slab-Pile Foundation}

4.1. Mechanical Analysis of Slab Structure. Figure 8 shows the settlement, horizontal deformation, and upper horizontal stress of the slabs for 1 day, 30 days, 60 days, and 730 days. As can be seen from Figure 8, the values for all parameters changed in the first month the most, and after two months, the consolidation was completed, and therefore, the change was small. The two lower partition slabs settled with different slopes; the first slab has a small settlement, the maximum is $1.5 \mathrm{~mm}$, and there is almost no horizontal displacement. The second slab has a maximum settlement of $14.1 \mathrm{~mm}$ and a horizontal displacement of approximately $0.3 \mathrm{~mm}$. In the $0-5 \mathrm{~m}$ area, the support of the two piles increases the overall stiffness of the foundation, and therefore, the settlement is small, the stiffness of the 5-10 m area is significantly smaller, and the tail of the lap is at the free end. Therefore, the settlement is more obvious here. There is a sedimentation mutation in the two slabs at $5 \mathrm{~m}$; however, because the connection between the bolster and the lower partition slab is a semirigid semihinged way of planting the PVC pipe, the upper part is backfilled with slag. It does not have any significant impact on the road. The overall deformation of the slab conforms to the expected situation, the overall settlement is processed in stages, and the horizontal deformation and settlement 
TABLE 2: Grading rate $i(\%)$ of different treatment technologies.

\begin{tabular}{lllll}
\hline Treatment technologies & $7 \mathrm{~d}$ & $30 \mathrm{~d}$ & $60 \mathrm{~d}$ & $730 \mathrm{~d}$ \\
\hline The lower partition slab-pile foundation & 0.023 & 0.062 & 0.07 & 0.073 \\
The deep-seated concrete slab & 0.068 & 0.168 & 0.17 & 0.183 \\
No treatment & 0.078 & 0.177 & 0.23 & 0.265 \\
\hline
\end{tabular}

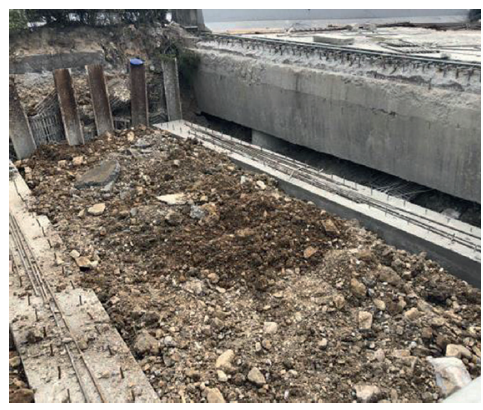

(a)

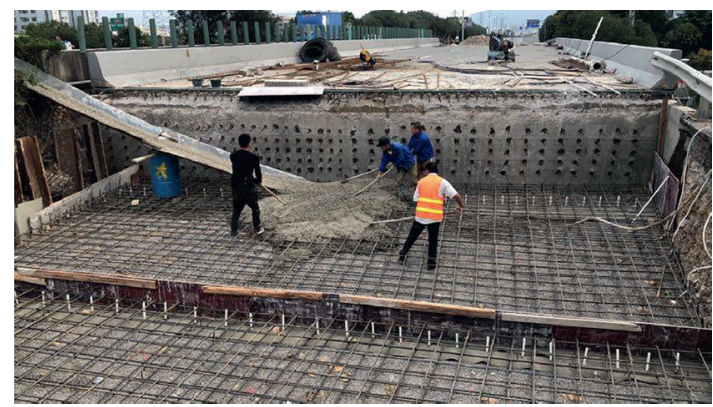

(b)

FIgURE 2: Construction site lower partition slab construction picture.

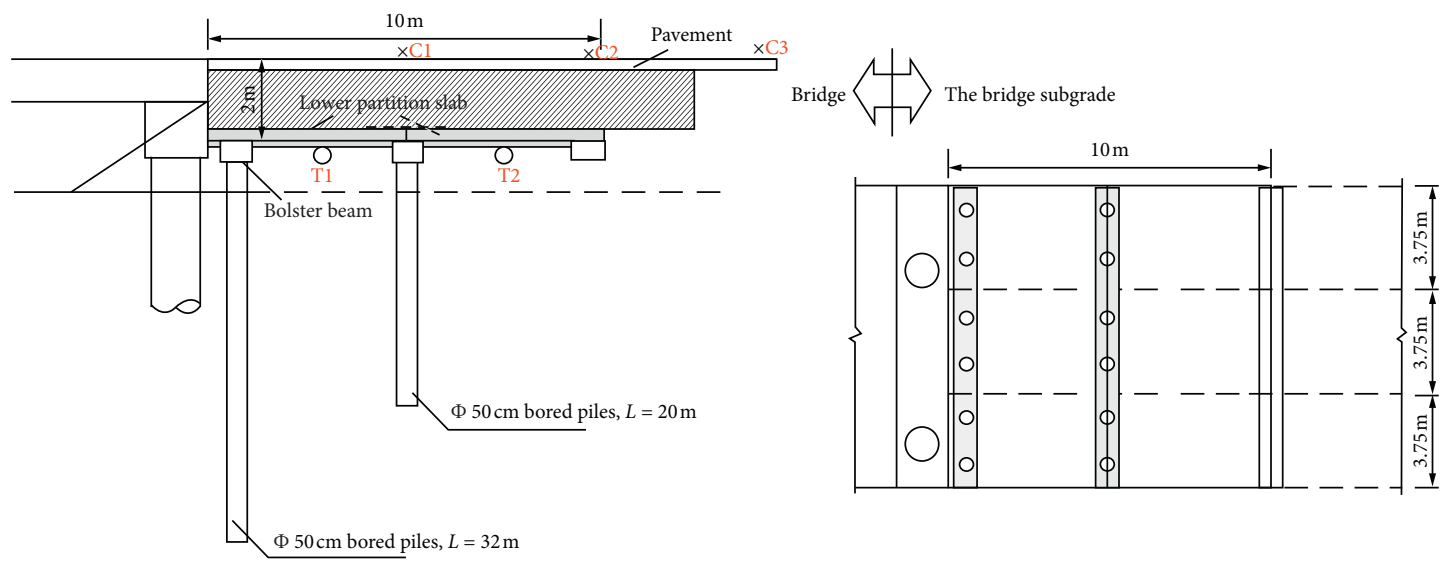

Figure 3: Lower partition slab-pile foundation design.

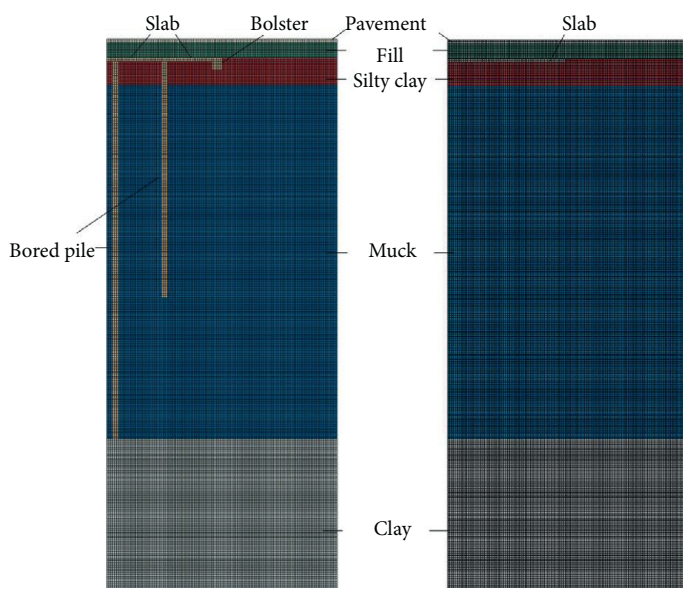

Figure 4: ABAQUS finite element simulation model. 


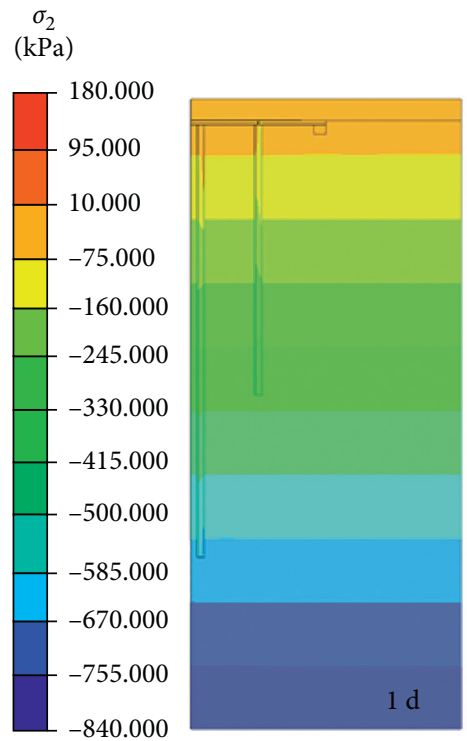

(a)

Pore pressure (kPa)

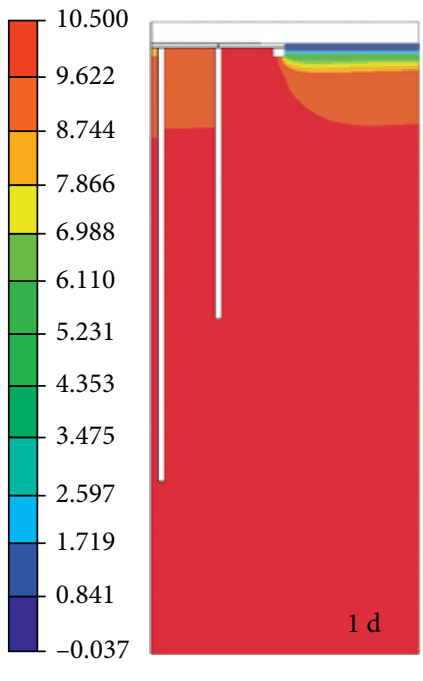

Settlement

(m)
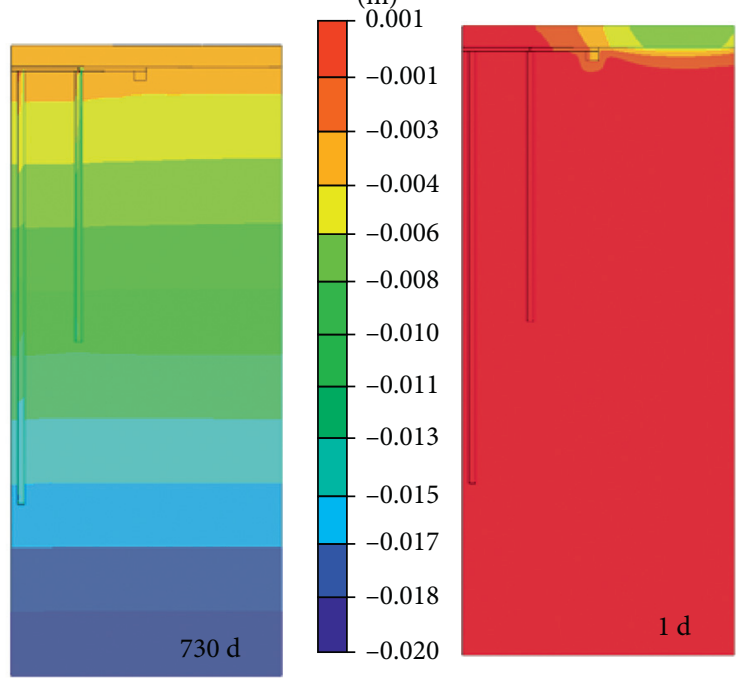

(b)

Displacement vector $(\mathrm{m})$
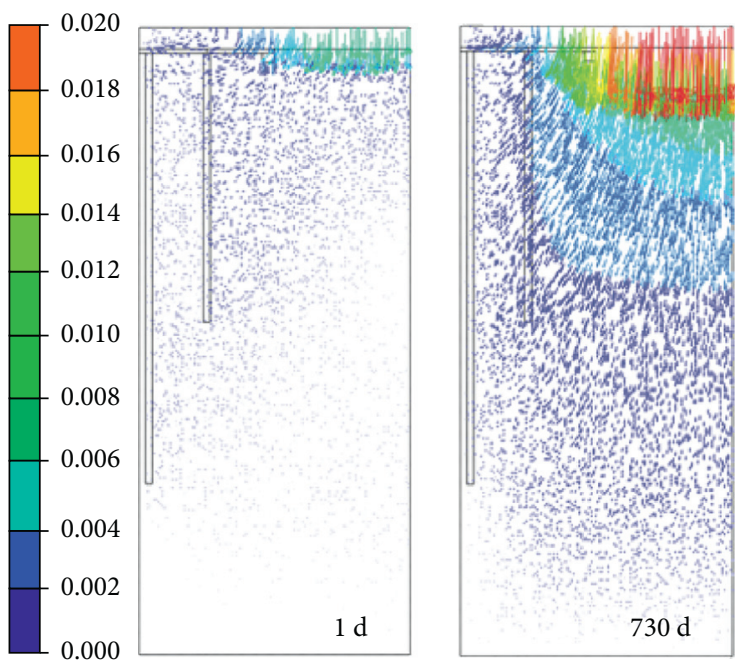

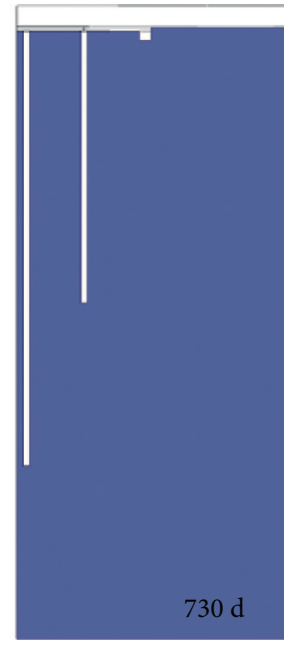

$30 \mathrm{~d}$

(c)

Figure 5: ABAQUS finite element simulation results: (a) vertical stress; (b) vertical displacement (c) pore pressure; and (d) displacement vector.

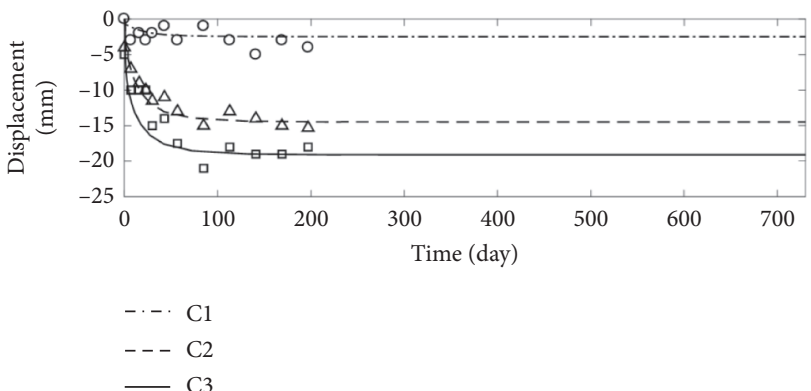

(a)

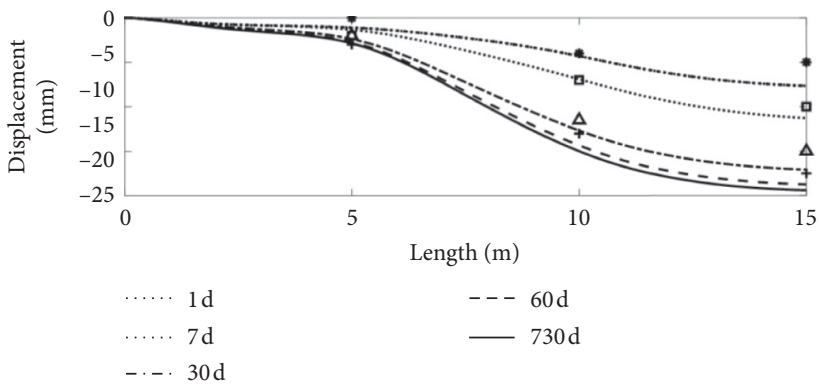

(b)

Figure 6: Comparison of settlement simulation results and field monitoring. 


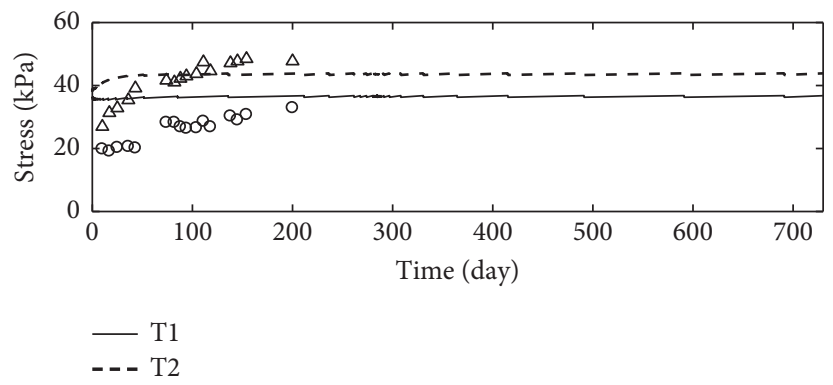

FIGURE 7: Comparison of soil pressure simulation results and field monitoring.

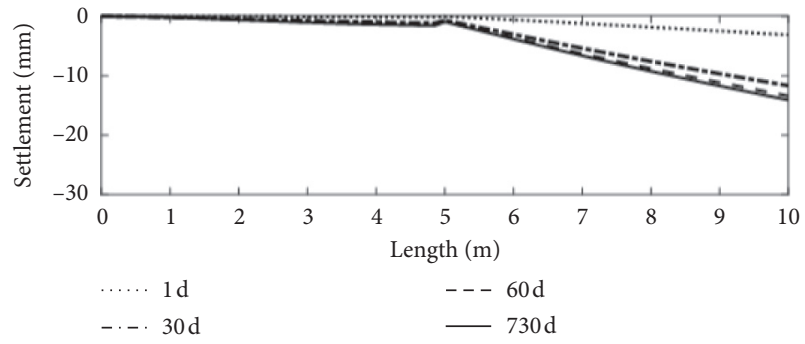

(a)

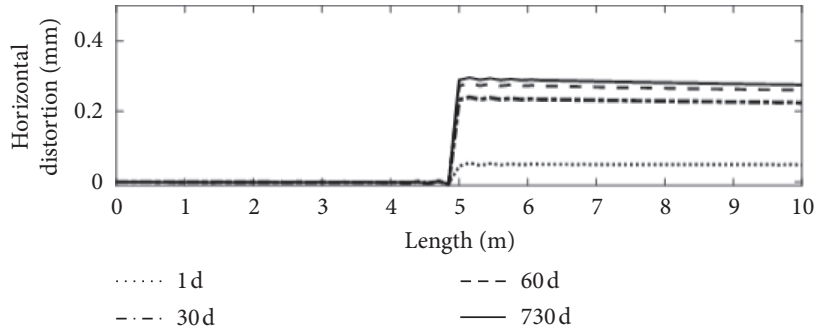

(b)

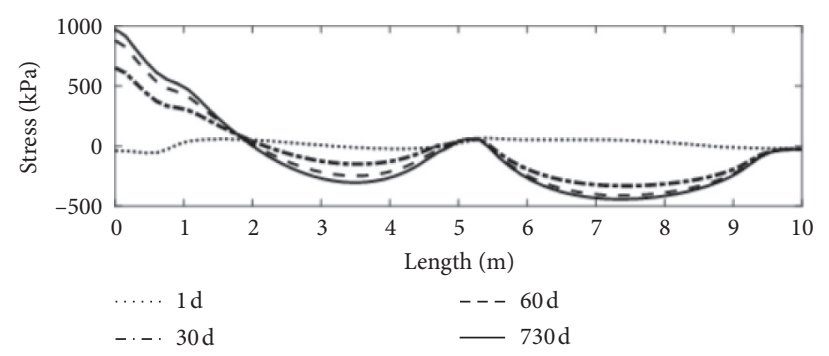

(c)

FIGURE 8: Lower partition slab simulation results.

of the slab are not large, which will not cause a structural failure. The axial force of the slab is shown in Figure 8(c). In addition to the large tensile stress near the abutment end, the maximum load is $972.8 \mathrm{kPa}$. The compressive stress is generated at the other positions. The maximum compressive stress is the maximum compressive stress of slab 1 which is $300.5 \mathrm{kPa}$, and the maximum compressive stress of slab 2 is $441.3 \mathrm{kPa}$.

4.2. Mechanical Analysis of Pile Structure. Figures 9 and 10 show the horizontal deformation, settlement, and pile side friction resistance of the two piles after normalization at 1 day, 30 days, 60 days, and 730 days. To facilitate the comparison of the force characteristics of the two piles, the ordinate has been normalized. It can be seen from the figure that, after 60 days, the consolidation is completed and the change is small. In addition, the right pile is shorter than the left pile length and the total side friction resistance is smaller than the left pile, which results in a settlement larger than that in the left pile. Under the upper load, the slab is displaced downward and the slab shifts to the left and the lower side owing to the gradual transition of the slab settlement trend from left to right. The horizontal displacement gradually decreases with an increase in depth. The horizontal displacement of the left pile is $0.19 \mathrm{~mm}$ and the maximum settlement is $0.16 \mathrm{~mm}$ after two years. After two years, the horizontal displacement is at most $1.1 \mathrm{~mm}$ and the settlement is at most $1.6 \mathrm{~mm}$ for the right pile. Under the action of the upper load, the side frictional resistance gradually functions and the whole is distributed in a $\mathrm{D}$ shape. The side friction resistance of the two piles gradually appeared from the top to the bottom along the depth direction of the pile. The frictional resistance of the pile in the middle section reaches the maximum value, and the side friction resistance of the $32 \mathrm{~m}$ pile was $5.43 \mathrm{kPa}$. The side friction resistance of the $20 \mathrm{~m}$ pile was $3.73 \mathrm{kPa}$. The negative frictional resistance occurs at the pile end on both sides. This is mainly because of the large rigidity of the pile. The compression deformation of the pile end soil under the load is greater than the deformation of the pile body, and thus negative frictional resistance occurs. In the middle of the pile, the soil on the pile side is stressed. When the soil deformation is reduced, the pile body moves downward relative to the soil body, and the side frictional resistance of the pile becomes positive, which prevents the pile from moving downward. 


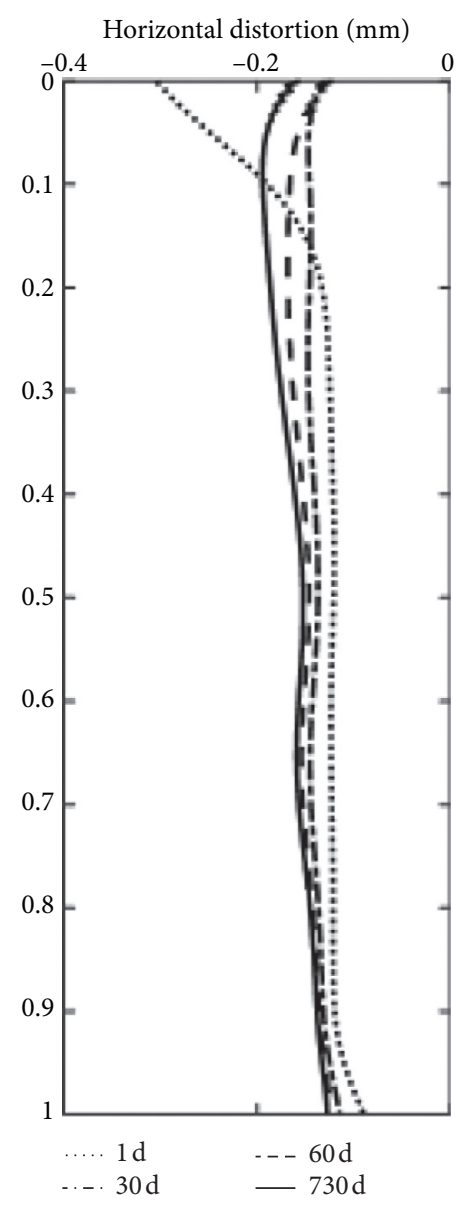

(a)

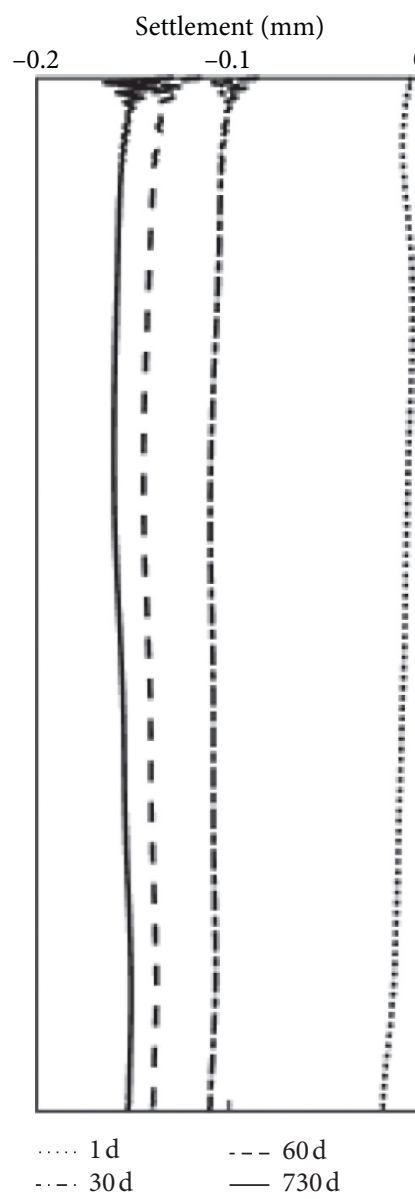

(b)

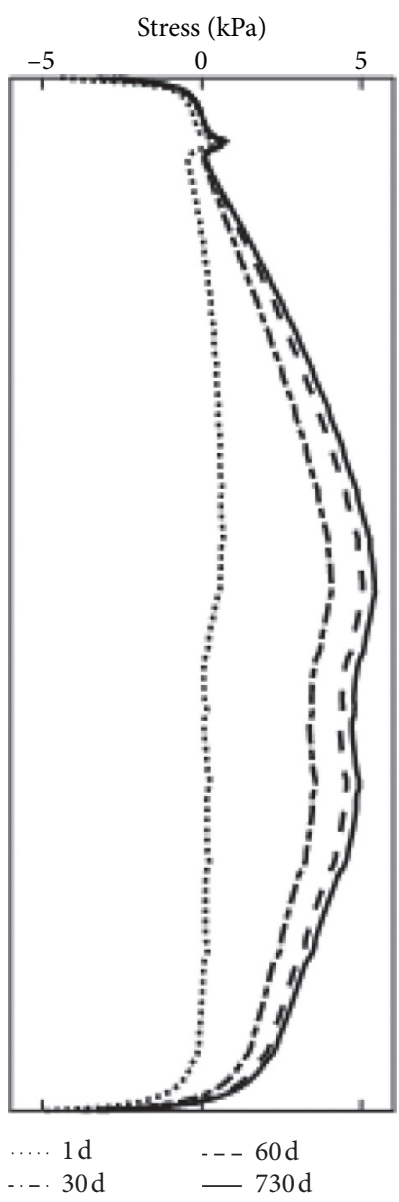

(c)

Figure 9: Pile $(32 \mathrm{~m})$ simulation results.

4.3. Comparison with Pure Slab Structure. Figure 11 shows the horizontal stress and vertical stress diagram of the composite foundation of the pile-slab and the simulation results of the pure slab. After 60 days, the overall force is basically stable. Both horizontal stresses produce a large stress concentration at the end of the slab, and both of them exhibit the phenomenon that the upper part of the upper part is pulled. However, the stress distribution of the composite foundation of the pile-slab is more uniform, and the overall stress level is only $1 / 3$ of that of the pure slab. The pile-slab composite foundation generates large vertical stress because of the support of the pile at the joint of the pile-slab, while the pure slab will have a large vertical stress concentration within $1 \mathrm{~m}$ of contact with the bridge end. In the nonstress concentrated area, the two vertical stress levels are not considerably different. Because the pure slab foundation has only one slab and can only rotate around the bridge end, a large stress concentration will be generated at the bridge end, and it will be damaged when the settlement is too large. The pile-slab composite foundation divides the stress into multiple sections for processing, and the structure is more stable and difficult to break.

Figure 12 shows the new pile-slab composite foundation, the deep slab technology, and the 7-day, 30-day, 60-day, and 730-day road surface settlement curves. The longitudinal slope change rate is an important indicator to determine whether the bridge-bridge jumps in the bridge-bridge joint section. $i=\Delta h / L$, where $i$ is the longitudinal slope change rate (\%) of the bridge section, $\Delta h$ is the selected road surface settlement ( $\mathrm{mm}$ ), and $L$ is the selected road surface length. We selected a $6 \mathrm{~m}$ length of the bridge end section to study the rate of change of the longitudinal slope. The results are shown in Table 2. It can be seen from the table that not only the longitudinal slope change rate is large but also the differential settlement occurs at the junction of the bridge and the road. At the junction between the abutment and the roadbed, a $13.4 \mathrm{~mm}$ step is formed. The pile-slab composite foundation and the deep-seated concrete slab technology can control the settlement into a curve. However, the longitudinal slope change rate of the deep-seated slab technology in 730 days was 2.5 times that of the composite foundation of piles and plates. This shows that the treatment method of the lower partition slab-pile foundation can better alleviate the settlement problem of the bridge end subgrade.

\section{Conclusion}

This paper introduces the case of using a new pile-slab composite foundation to deal with bridge end jumping. 


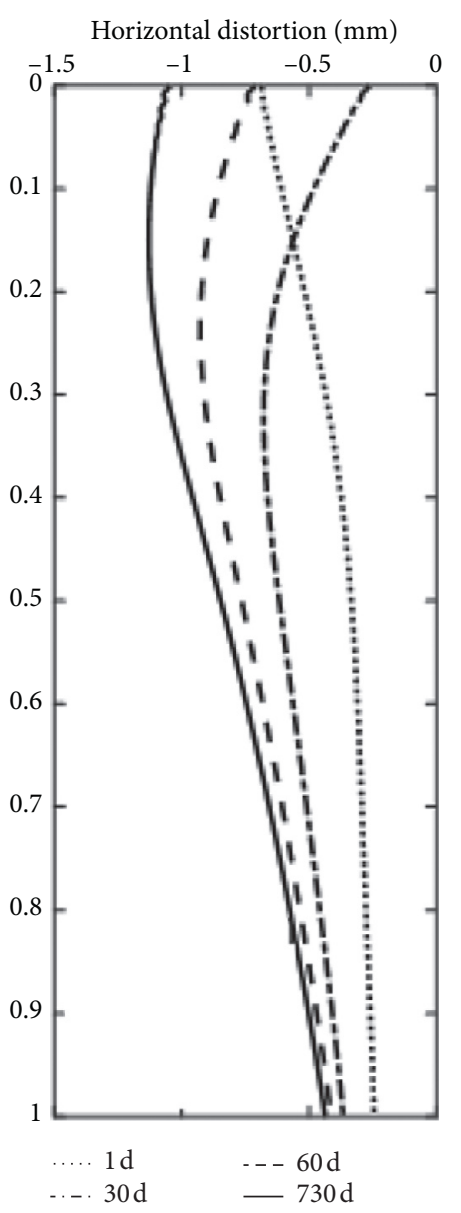

(a)

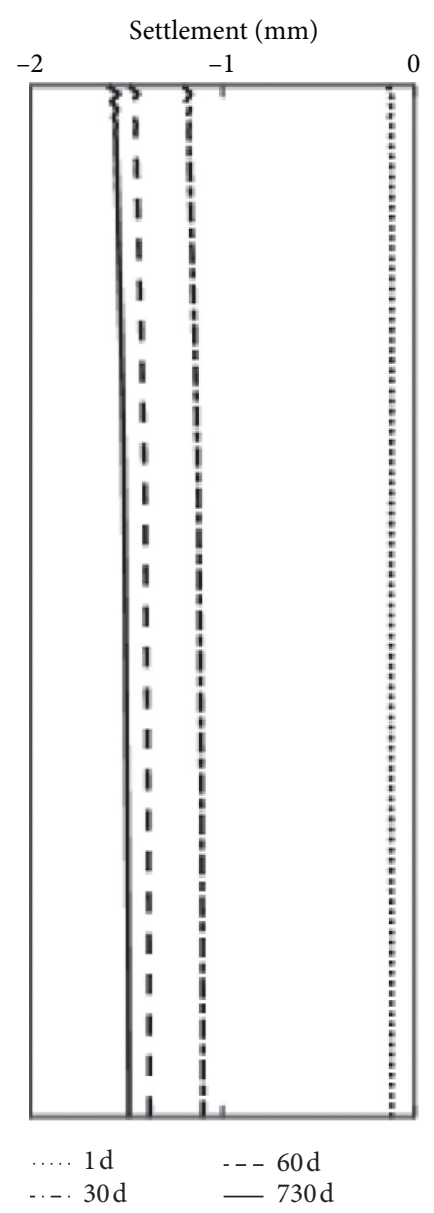

(b)

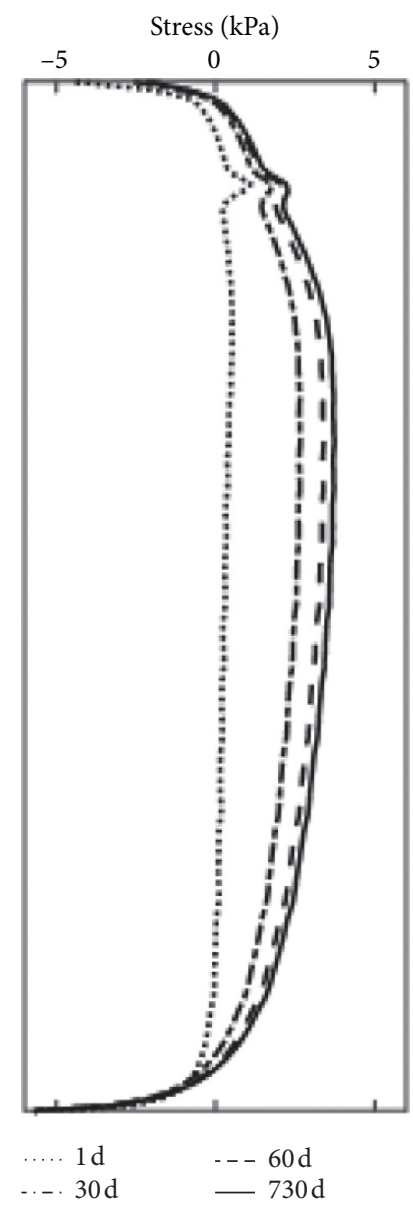

(c)

Figure 10: Pile $(20 \mathrm{~m})$ simulation results.

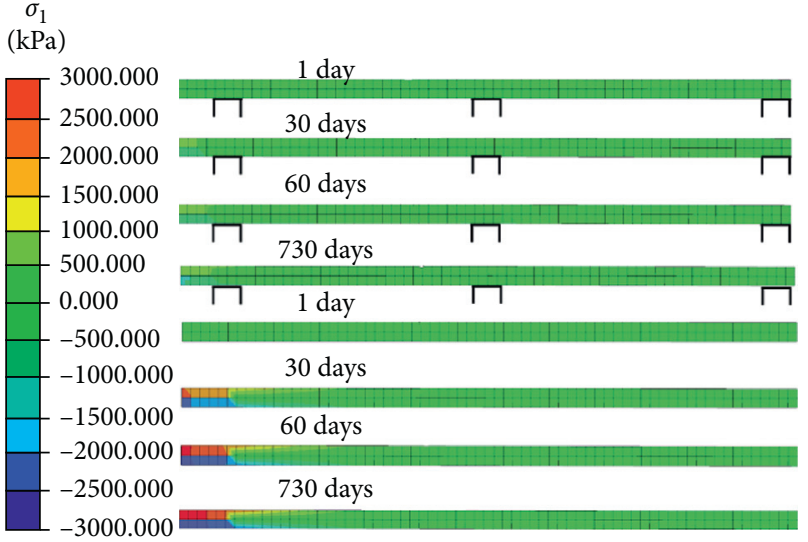

(a)

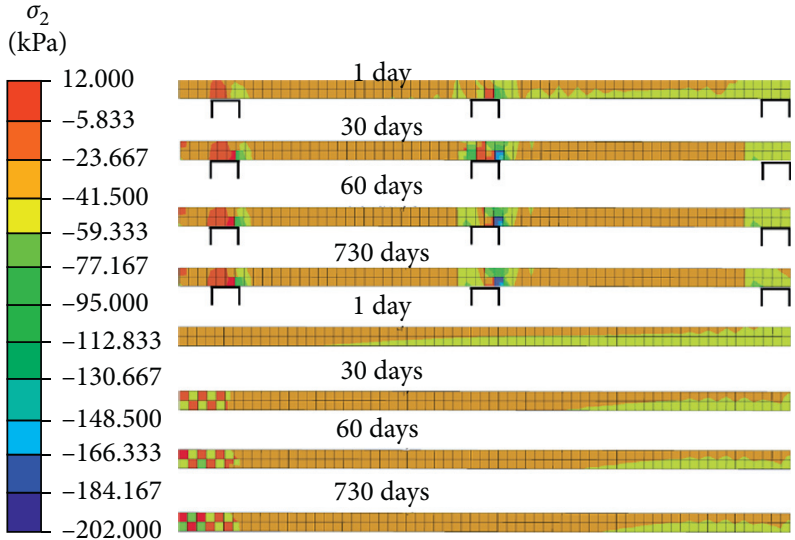

(b)

Figure 11: Comparison of the force of the lower partition slab-pile foundation and deep-seated concrete slab.

First, the treatment method of the lower partition slab-pile foundation is proposed, and the construction method is introduced in detail. Based on the results of on-site monitoring and finite element modeling analysis, the following conclusions can be drawn:
(1) For the first time, the method of treating bridge end with integrated concrete baffle-pile foundation is proposed. By means of the overall action of piles and slabs, the foundation stress in the foundation is dispersed, which not only can reduce the settlement 

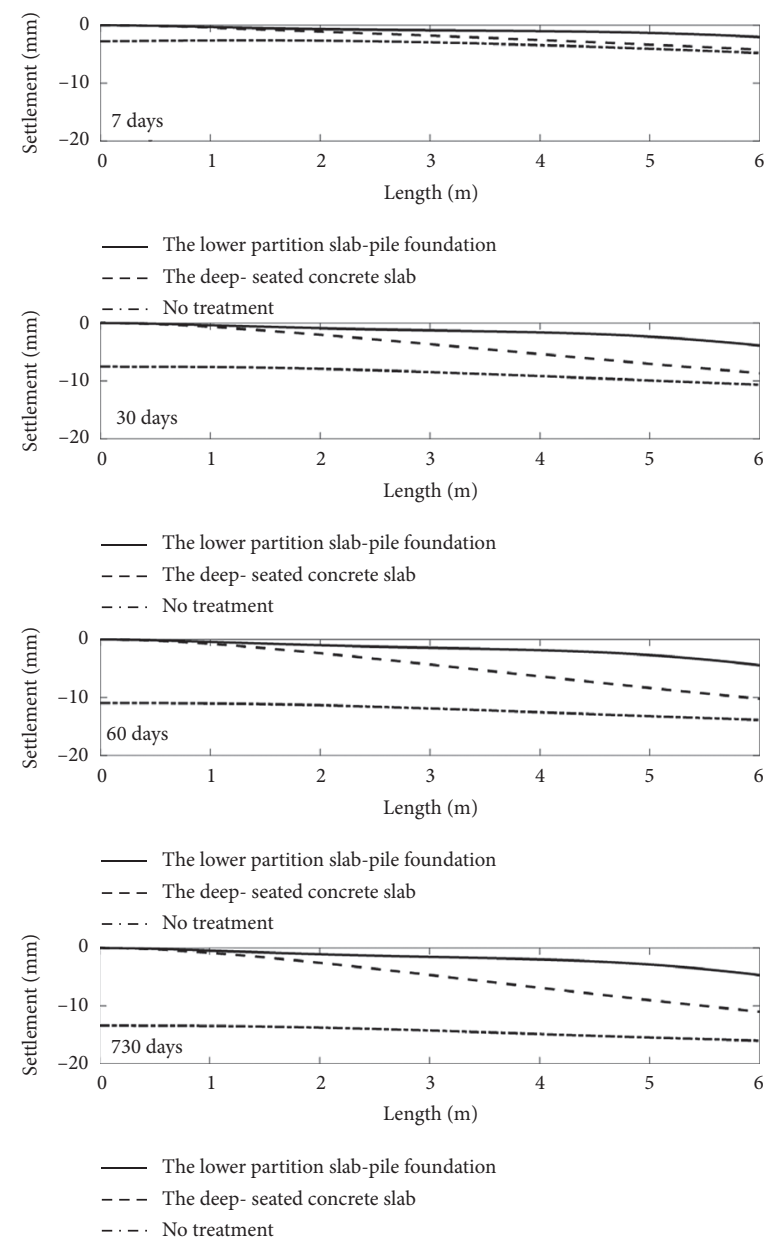

FIGURE 12: Comparison of treatment and disposal effects of different treatment technologies.

but also improve the differential settlement of roads and bridges by ensuring smooth transitions based on certain rules.

(2) By embedding the monitoring instrument, the longterm settlement, the change in soil pressure was measured, and the soil pressure developed under slab 1 was found to be relatively stable; it gradually increased from $27 \mathrm{kPa}$ to $33 \mathrm{kPa}$. The pressure change in the soil under slab 2 is relatively large, gradually increasing from $27 \mathrm{kPa}$ to $48 \mathrm{kPa}$, reflecting the soil stress of the lower partition. The analysis showed that the lower settlement of the concrete lower partition avoids bridge end jumping. The effect of the phenomenon is good.

(3) For the transition section of Zhuxi Bridge end, we established the same size FEM model, combined with the field measured data and analyzed and predicted the long-term settlement of the bridge end transition section. The results showed that the long-term effect of the lower partition slab-pile foundation on the settlement treatment is very good. According to the assumption, the transition section of the bridge end is smooth, and the mechanical properties of the bridge were analyzed. The overall frictional resistance of the pile was D-shaped. The frictional resistance of the pile in the middle section reaches the maximum value, and the negative frictional resistance occurs at the pile ends. The maximum side friction resistance of the $32 \mathrm{~m}$ pile is $5.43 \mathrm{kPa}$, and the side frictional resistance is $3.73 \mathrm{kPa}$.

(4) By the finite element method, the results for the lower partition slab-pile foundation is compared with that of the traditional treatment process. The horizontal stresses of both methods produce a large stress concentration at the slab end, and both methods also exhibit the phenomenon that the upper part under pressure is pulled. However, the stress distribution of the composite foundation of the pileslab is more uniform, and the horizontal stress level is only $1 / 3$ of that of the pure slab. The pile-slab composite foundation generates a large stress concentration at the joint of the pile-slab due to the higher vertical stress of the pile slab, and the pure slab will have a large vertical stress concentration within $1 \mathrm{~m}$ of the contact with the bridge end, owing to the pile foundation. The bearing capacity of the foundation is enhanced, and the longitudinal slope change rate of the deep-seated concrete slab technology is 2.5 times that of the composite foundation 
of the pile slab. This shows that the lower partition slab-pile foundation treatment method can better deal with the problem of bridge end transition.

The focus of this work is to propose a new method for dealing with the bridge end bump problem with a new pileslab composite foundation. Three aspects of the new construction method (mechanical analysis of pile structure, mechanical analysis of slab structure, and final effect of settlement control) are studied through real cases combined with field monitoring and numerical simulation and compared with the original method. Future work will focus on the optimization design of the new pile-slab composite foundation.

\section{Data Availability}

The data used to support the findings of this study are included within the article

\section{Conflicts of Interest}

The authors declare that they have no conflicts of interest.

\section{Acknowledgments}

This research work was funded by the National Nature Science Foundation of China (Nos. 51808407; 41572284; and 51578427), Public Technology Application Research Project of Zhejiang Province (2014C33015), and Wenzhou Major Science and Technology Project (ZS2017002).

\section{References}

[1] H. K. W. Wong and J. C. Small, "Effect of orientation of approach slabs on pavement deformation," Journal of Transportation Engineering, vol. 120, no. 4, pp. 590-602, 1994.

[2] X. M. Shi, C. S. Cai, G. Z. Voyiadjis, and Z. Zhang, Finite Element Analysis of Concrete Approach Slab on Soil Embankment, ASCE, Reston, VA, USA, 2004.

[3] C. S. Cai, X. M. Shi, G. Z. Voyiadjis, and Z. J. Zhang, "Structural performance of bridge approach slabs under given embankment settlement," Journal of Bridge Engineering, vol. 10, no. 4, pp. 482-489, 2005.

[4] J. L. Robison and R. Luna, Deformation Analysis of Modeling of Missouri Bridge Approach Embankments, ASCE, Reston, VA, USA, 2004.

[5] D.-H. Chen, S. Nazarian, and J. Bilyeu, "Failure analysis of a bridge embankment with cracked approach slabs and leaking sand," Journal of Performance of Constructed Facilities, vol. 21, no. 5, pp. 375-381, 2007.

[6] S. Roy and G. Thiagarajan, "Nonlinear finite-element analysis of reinforced concrete bridge approach slab," Journal of Bridge Engineering, vol. 12, no. 6, pp. 801-806, 2007.

[7] H. H. Nassif, T. Abu-Amra, N. Suksawang, Y. Khodair, and N. Shah, "Field investigation and performance of bridge approach slabs," Structure and Infrastructure Engineering, vol. 5, no. 2, pp. 105-121, 2009.

[8] X. Yi-qiang, S. Yun, J. Fu-gen, L. Wei, and Z. Shu-ren, "Case study of the deep-seated concrete slab for settlement control at bridge approach embankment," Journal of Harbin Institute of Technology, vol. 42, no. 1, pp. 163-167, 2010, in Chinese.
[9] Q. Chen and M. Abu-Farsakh, "Mitigating the bridge end bump problem: a case study of a new approach slab system with geosynthetic reinforced soil foundation," Geotextiles and Geomembranes, vol. 44, no. 1, pp. 39-50, 2016.

[10] A. J. Puppala, P. Ruttanaporamakul, and S. S. C. Congress, "Design and construction of lightweight EPS geofoam embedded geomaterial embankment system for control of settlements," Geotextiles and Geomembranes, vol. 47, no. 3, pp. 295-305, 2019.

[11] K. Q. Lin and I. H. Wong, "Use of deep cement mixing to reduce settlements at bridge approaches," Journal of Geotechnical and Geoenvironmental Engineering, vol. 125, no. 4, pp. 309-320, 1999.

[12] K. N. Gunalan, C. Christensen, C. Hansen, and K. Hirschmugl, Accelerating Construction of Bridge Abutments: Legacy Parkway Project, UT, ASCE, Reston, VA, USA, 2004.

[13] R. M. Bakeer, M. A. Shutt, J. Zhong, S. C. Das, and M. Morvant, "Performance of pile-supported bridge approach slabs," Journal of Bridge Engineering, vol. 10, no. 2, pp. 228-237, 2005.

[14] J. Zhang, J. Zheng, D. Zhao, and S. Chen, "Field study on performance of new technique of geosynthetic-reinforced and pile-supported embankment at bridge approach," Science China Technological Sciences, vol. 59, no. 1, pp. 162-174, 2015.

[15] D. Xiao, G. L. Jiang, D. Liao, Y. F. Hu, and X. F. Liu, "Influence of cement-fly ash-gravel pile-supported approach embankment on abutment piles in soft ground," Journal of Rock Mechanics and Geotechnical Engineering, vol. 10, no. 5, pp. 977-985, 2018.

[16] Z.-X. Wu, H. Ji, J. Han, and C. Yu, "Numerical modelling of granular column collapse using coupled Eulerian-Lagrangian technique with critical state soil model," Engineering Computations, vol. 7, pp. 2480-2504, 2019.

[17] Z.-Y. Yin, Z. Jin, P. Kotronis, and Z.-X. Wu, "Novel SPH SIMSAND-based approach for modeling of granular collapse," International Journal of Geomechanics, vol. 18, Article ID 04018156, 2018. 